\title{
Reconstruction and Practice of Coarse Slime System of Chengjiao Coal Preparation Plant
}

\author{
Zhanying Ren, Renshu Yang \\ School of Mechanics and Civil Engineering, \\ China University of Mining and Technology, \\ Beijing, China
}

\begin{abstract}
In this paper, problems in coal handling system and practice of Chengjiao coal preparation plant is tested and analyzed in detail, and $I$ have put forward solutions for problems in coal handling system. The best production program of Chengjiao coal preparation plant was chose through program comparing. After the implementation of the program, the annual clean coal production can be increased by 162,400 tons, and economic benefits are significant.
\end{abstract}

Keywords-coal slim; flotation; program,; reformation

\section{INTRODUCTION}

Designed capacity of Chengjiao Coal preparation plant is $6 \mathrm{MT} / \mathrm{a}$, it will be achieved in two projects, designed capacity of the first project is 4 MT/a, pre-desliming separation in heavy-medium, separation of coarse coal and flotation are used together. Chengjiao Coal preparation plant is a mine Coal preparation plant, coal was mined from Gaoyang and Baibiguan. Shanxi Formation (on coal) seam No. 1,2,3 and Taiyuan group (under coal) seam No. 9,10,11 are mined mainly in Gaoyang. On coal has high-ash and low-sulfur content., It contains sulfur of $0.6 \%$ and ash of $40 \%$. However, under coal has high-sulfur and low-ash coal, sulfur of it is $2.5 \%$, ash of it is $28 \%$.
As a result of the extent of coal mining mechanization increased, the slime content of coal increases, the proportion of flotation increases. So flotation are being attentioned more and more, shows a booming trend, and shows in the following main aspects: (1) Simple process, efficient become a modern design trend of coal preparation, direct flotation process is being attentioned more and more, and to achieve direct flotation, the flotation machine with appropriate capacity must be selected. Flotator with largescale processing capacity is a modern trend of coal preparation [1]. (2) The research of dense medium cyclone is deepening, the minimum size of flotation coal is decreasing, flotation coal size is getting smaller and smaller, it requires the flotation equipment to strengthen the separation of fine coal. As a result of fine coal pollution to traditional flotator, the best effect of flotation is difficult to achieve. Therefore, flotation column and the jet flotator with better separation effect of fine coal made a rapid development [2, 3]. Typical representatives of this flotator: Jameson flotation column of Australia, CPT of Canadian, Cyclone-static micro-bubble flotation column [4, 5].

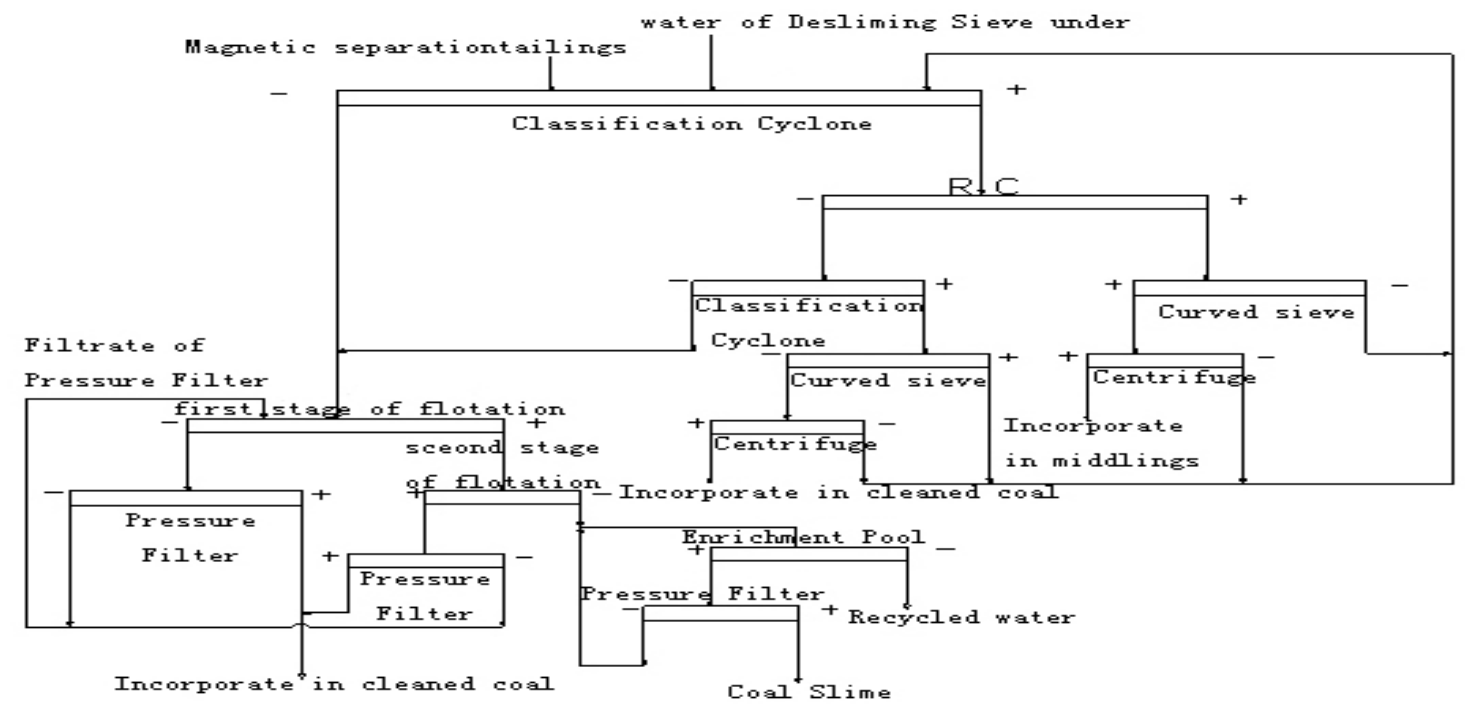

Figure 1. Coal slime separation process of Chengjiao Coal preparation plant. 


\section{STATUS AND PROBLEMS OF COAL PROCESSING OF CHENGJIAO COAL PREPARATION PLANT}

Flotation and coarse coal separation are used in Chengjiao Coal preparation plant, flotation is two series of flotation by Jameson flotator. Clean coal of flotation is dehydrated by pressure filter, tailing coal of flotation is enriched and pressured; coarse coal slime is deal by coarse coal slime separator (RC) made in Australia. This process is shown in Figure 1.

Jameson flotator is composited of several small-scale flotation columns. Throughput of every flotation column is $70-90 \mathrm{~m}^{3} / \mathrm{h}$, the amount of flotation columns is chose according to the different feeding capacity of coal and coal slime handling capacity. Every flotator of Chengjiao Coal preparation plant uses 24 flotation columns, coal pulp throughput is $1920 \mathrm{~m}^{3} / \mathrm{h}$, the pressure is about $150 \mathrm{Kpa}$. The principle is as follows: coal pulp is feed into each flotation column through flotator distribution boxes by pump, the pressure reaches $150 \mathrm{Kpa}$, the speed of coal pulp reaches 17 $\mathrm{m} / \mathrm{s}$. High-speed flow of coal pulp makes the flotator becomes vacuum, air is inhalated into flotator through the air supply pipe, then the air flowed into air distribution box, and then flowed into the flotator through the air imports of each flotation column, the air is cut into small thin foam by the high-speed flow of coal pulp, the coal mixed with small thin foam uniformly, at last complete separation in the under catheter.

Problems of Jameson flotator: (1) Separation of coal pulp is completed in the under catheter, but the time coal pulp exist in the under catheter is only $0.2-0.4$ seconds, separation time is too short to separate inadequately, effect of flotation is bad. (2) It is sensitive to changes of coal quality, flotation effect of easily float coal is better, flotation effect of easy float coal is deteriorated rapidly. (3) It is sensitive to changes of the system, flotation effect of is deteriorated rapidly when the quality of flotation recycled water is poor and large volume circle of fine mud.

After a year of trial operation, flotation had been unable to meet the designed requirement, flotation yield declined as increase of coal, and ash of tailing coal is reduced. The volume of original designed floating coal slime in Chengjiao Coal preparation plant is $16.47 \%$, according to statistic of product result in 2007, the volume of coal slime in raw coal is $15.04 \%$, The volume of coal slime in secondary coal is $7.25 \%$, The volume of coal slime in floating coal is $18.73 \%$, the main reason for increased coal slime is the improvement of coal mining mechanization and the use of moving-sieve jig. Because of the volume of coal slime is increased, the yield of flotation is reduced significantly, concentration of clean coal is reduced, effect of pressure filter is impacted, the burden of concentrate filter press is increased. Size of float-feeding coal which is lager than $0.375 \mathrm{~mm}$ is more than $20 \%$ of all coal, because of the problem of hydrocyclone classification effect. Jameson flotator cannot separate coarse coal effectively (shown in Table 3: Screening Test Table), so the ash of tailing coal is reduced.

\section{SYSTEM TESTING AND RESEARCH}

\section{A. One possible solution}

To solute the problems that a large number of foam accumulated in richment pool and cycle pool, the filtrate which directly feed into pressure filter of richment pool is changed to feed into materials barrels of first stage of flotation. After the filtrate was changed into closed-cycle, phenomenon of a large number of foam accumulated in richment pool and cycle pool is eased. However, the effect of flotation had not been soluted fundamentally, so phenomenon of a large number of foam accumulated in richment pool and cycle pool is still very serious.

\section{B. Another possible solution}

To solute the problem that effect of flotation becomes worse for the volume of withing-coal increased, repeated testing, and trialing are made in stage of different volume of withing-coal. The result is shown in Table I.

TABLE I. TEST RESULTS OF SYSTEM INDICATORS.

\begin{tabular}{|c|c|c|c|c|}
\hline & & Flotation & Ash of & \\
Test & $\begin{array}{c}\text { The } \\
\text { Volume of } \\
\text { Coal (t/h) }\end{array}$ & $\begin{array}{c}\text { Concentrate } \\
\text { Coal }\end{array}$ & $\begin{array}{c}\text { Flotation } \\
\text { Tailing coal }\end{array}$ & Yield \\
\cline { 3 - 5 } & 200 & 7.69 & Aad \% & $\%$ \\
\hline 1 & 400 & 7.88 & 42.51 & 72.35 \\
\hline 3 & 500 & 6.6 & 38.21 & 73.42 \\
\hline 4 & 600 & 6.45 & 32.45 & 68.55 \\
\hline 5 & 700 & 6.12 & 27.66 & 58.37 \\
\hline 6 & 800 & 5.85 & 24.88 & 49.08 \\
\hline
\end{tabular}

Data in Table I shows these: when the volume of withing-coal of raw coal is less than $400 \mathrm{t} / \mathrm{h}$, the flotation yield remained a basic level; when the volume of withingcoal is $400-500 \mathrm{t} / \mathrm{h}$, the flotation yield decreases in some degree, and as the volume of withing-coal increases, yield, ash of flotation tailing coal, and ash of flotation clean coal are all in the trend of decrease; when the volume of withing-coal is $800 \mathrm{t} / \mathrm{h}$, ash of flotation tailing coal is about $25 \%$. So that the largest production capacity of Chengjiao Coal preparation plant is $400-500 \mathrm{t} / \mathrm{h}$, that is only about half of designed withing-coal volume (952t/h), flotation system must be reformed in order to solve the problem of flotation system fundamentally.

\section{Particle size analysis of flotation feeding coal, concentrate coal, and tailing coal}

Particle size analysis data of flotation feed coal, concentrate coal, tailing coal is shown in Table II. Table II shows that: Separation of fine coal slime by Jameson flotator is better, while separation of coarse coal slime is less effective, the result is same as theory of Jameson flotator. Flotation feeding coal of Chengjiao Coal preparation plant is coarse coal (the volume of coal size $>0.25 \mathrm{~mm}$ accounted for about $30 \%$ ), the ash of coarse 
coal slime is very low (accumulated ash is less than $4.5 \%$ ), and it is the main reason that ash of tailing coal cannot be increased in Chengjiao Coal Preparation plant too. So we believe that selection of flotator in the early stage of planting factory exist problems, flotation must be reformed in order to change the quo status of flotation.

\section{OPTIMIZATION AND REFORMATION OF THE SYSTEM}

Coal of Chengjiao Coal Preparation plant is coarse, belong to coal which float easily. The Fine mud polluted the clean coal of flotation little, we choose XJM flotator, it separates the coarse coal well, clean coal of flotation is processed by pressure filter. Following programs are put forward:

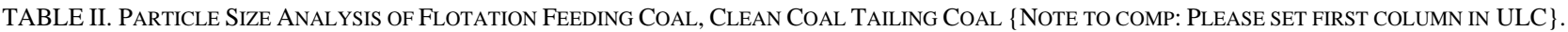

\begin{tabular}{|c|c|c|c|c|c|c|c|c|c|c|c|c|c|c|}
\hline \multirow{3}{*}{$\begin{array}{c}\text { Size } \\
\text { um }\end{array}$} & \multirow{3}{*}{ 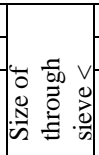 } & \multicolumn{4}{|c|}{ Feeding coal } & \multicolumn{4}{|c|}{ Clean coal first stage and second stage } & \multicolumn{4}{|c|}{ Total tailing coal } & \multirow{3}{*}{$\begin{array}{c}\text { Yield } \\
\text { of } \\
\text { grain } \\
\text { size } \\
\%\end{array}$} \\
\hline & & \multicolumn{2}{|c|}{ Individual } & \multicolumn{2}{|c|}{ Cumulative } & \multicolumn{2}{|c|}{ Individual } & \multicolumn{2}{|c|}{ Cumulative } & \multicolumn{2}{|c|}{ Individual } & \multicolumn{2}{|c|}{ Cumulative } & \\
\hline & & $\begin{array}{c}\text { Yield } \\
\%\end{array}$ & $\begin{array}{c}\text { Ash } \\
\%\end{array}$ & $\begin{array}{c}\text { Yield } \\
\%\end{array}$ & $\begin{array}{c}\text { Ash } \\
\%\end{array}$ & $\begin{array}{c}\text { Yield } \\
\%\end{array}$ & $\begin{array}{c}\text { Ash } \\
\%\end{array}$ & $\begin{array}{c}\text { Yield } \\
\%\end{array}$ & $\begin{array}{c}\text { Ash } \\
\%\end{array}$ & $\begin{array}{c}\text { Yield } \\
\%\end{array}$ & $\begin{array}{c}\text { Ash } \\
\%\end{array}$ & $\begin{array}{c}\text { Yield } \\
\%\end{array}$ & $\begin{array}{c}\text { Ash } \\
\%\end{array}$ & \\
\hline$<45$ & 0.05 & 40.6 & 22.52 & 48 & 22.5 & 41.22 & 8.02 & 35.2 & 8.52 & 36 & 38.05 & 42.6 & 38.1 & 37.9 \\
\hline $45-75$ & 0.08 & 8.42 & 15.34 & 46 & 20.5 & 12.45 & 4.25 & 47.7 & 7.4 & 4.3 & 13.01 & 46.9 & 35.7 & 75.74 \\
\hline $75-125$ & 0.13 & 14.92 & 8.05 & 69 & 19.9 & 16.45 & 5.07 & 64.1 & 6.81 & 17 & 14.35 & 63.5 & 30.2 & 65.21 \\
\hline $125-180$ & 0.18 & 7.75 & 6.28 & 79 & 18.2 & 14.33 & 4.55 & 78.5 & 6.39 & 8.8 & 18.54 & 72.3 & 28.7 & 75.28 \\
\hline $180-250$ & 0.25 & 10.66 & 4.89 & 87 & 17 & 9.38 & 4.99 & 87.8 & 6.24 & 14 & 16.37 & 84 & 27 & 55.48 \\
\hline $250-335$ & 0.34 & 10.33 & 4.16 & 95 & 16 & 3.97 & 3.06 & 94.8 & 6.01 & 9.6 & 13.31 & 92.6 & 25.8 & 48.7 \\
\hline$>335$ & & 7.32 & 3.96 & 100 & 14.6 & 3.2 & 2.6 & 100 & 5.66 & 10 & 7.01 & 100 & 23.6 & 50.06 \\
\hline Cumulative & & 100 & & & 14.6 & 100 & & & 5.66 & & & & 23.4 & \\
\hline Total sample & & & & & 14.6 & & & & 5.7 & & & & 23.7 & \\
\hline
\end{tabular}

Program 1: Removed the Two Jameson flotator, and selected the XJM-20 flotator. Feeding coal of flotator come from the hydrocyclone enrichment directly in the program, clean coal of flotation is processing by pressure filter in concentrate coal barrels. The feeding coal barrels and pump of first flotation is changed into feeding coal barrels and pump of the modified flotator, and the feeding coal barrels and pump of second flotation can be changed into concentrate coal barrels of flotation and feeding pump of pressure filter. The quantity of engineering is less, cost of equipment is less, and transforming process do not impact production, technology system is stable, product specifications is reliable after reformation.

Program 2: Removed the second stage of flotation ,the new XJM-20 flotator series after the first stage of flotation, the first stage of flotation use the present technology, and the feeding coal barrels and pump of second flotation is changed to use for the feeding coal barrels and pump of the new flotator. Use a new pump as feeding pump of pressure filter. A concentrate coal barrel may need to be increased according to the actual production. The quantity of engineering is less, cost of equipment is less, and transforming process do not impact production significantly, but flotation effect of Jameson flotator deteriorated significantly as increasing of coal capacity, the low clean coal concentration will impact dehydration of clean coal. So the effect of the reformation needs to be tested in actual production.
Program 3: The present flotation system keep unchanged, the new XJM-20 flotator series after the second stage of flotation, and it need to increase a barrel and a pump as the feeding coal barrel and pump of the XJM-20 flotator, take a new pump as feeding pump of pressure filter. A barrel of clean coal may need to be increased according to the actual production. The quantity of engineering is more relatively, cost of equipment will reduce; however, subsequent running costs will be more relatively. And flotation effect of Jameson flotator deteriorated significantly as increasing of coal capacity, the low clean coal concentration will impact dehydration of clean coal. So the effect of the reformation needs to be tested in actual production.

Program 4: Parallel using the two Jameson flotator, and feeding coal at the same time, the new XJM-20 flotator series after every Jameson flotator. Better effect of flotation need larger throughput in Jameson flotator, so the cycle volume of coal $\left(300-400 \mathrm{~m}^{3}\right)$ cannot meet the designed throughput of flotator if the two Jameson flotator are used parallel, so that the present technology of flotator must be reformed, and it will impact the production when reforming. The effect of the reformation needs to be tested in actual production. Therefore, we give up the program. Economic indicators of reforming program show in Table III. 
TABLE III. COMPARISON OF REFORMING PROGRAM.

\begin{tabular}{|c|c|c|c|c|c|c|c|}
\hline \multirow[b]{2}{*}{ Program } & \multicolumn{3}{|c|}{ Equipment Selection (Number) } & \multirow{2}{*}{$\begin{array}{c}\text { Investment } \\
\text { (Yuan) }\end{array}$} & \multirow{2}{*}{$\begin{array}{l}\text { Costs of } \\
\text { Processing } \\
\text { (Yuan/t) }\end{array}$} & \multirow[b]{2}{*}{$\begin{array}{c}\text { Profit } \\
\text { (Yuan/a) }\end{array}$} & \multirow[b]{2}{*}{$\begin{array}{c}\text { Year of } \\
\text { Return (a) }\end{array}$} \\
\hline & Flotator & $\begin{array}{c}\text { Pressure } \\
\text { Filter }\end{array}$ & Fan & & & & \\
\hline 1 & 4 & 1 & 4 & 24104000 & 247200 & 45640000 & 0.53 \\
\hline 2 & 3 & 1 & 4 & 22464000 & 256900 & 45500000 & 0.49 \\
\hline 3 & 3 & 1 & 4 & 23124000 & 293000 & 44940000 & 0.51 \\
\hline
\end{tabular}

\section{CONCLUSION}

We have chosen program 1. The investment of it is $24,104,000$ Yuan, costs of processing is 247,200 Yuan every year, annual profit is 45,640,000 Yuan. So the production costs of the program is low, annual profit of the program is maximum. And production technique is mature and reliable, technology is flexible and reliable, production specifications are stable and reliable.

After transformation of the flotation system, tailing coal will be reduced by 162,400 tons. Land for piling up pollutants will reduce, it is conducive to environmental protection.

\section{ACKNOWLEDGMENTS}

The research work was supported by China University of Mining and Technology, Beijing

\section{REFERENCES}

[1] H. Ucbeyiay, Hydrophobic flocculation and Box-Wilson experimental design for beneficiating fine coal. Fuel Processing Technology, 2013.

[2] F. Jiangang, C. Kaida, W. Hui, et al., Recovering molybdenite from ultrafine waste tailings by oil agglomerate flotation. Minerals Engineering. 2012.

[3] S. Song, X. Zhang, B. Yang, et al., Flotation of molybdenite fines as hydrophobic agglomerates. Separation and Purification Technology, 2012.

[4] W.-z. Yin, X.-s. Yang, D.-p. Zhou, et al., Shear hydrophobic flocculation and flotation of ultrafine Anshan hematite using sodium oleate. Transactions of Nonferrous Metals Society of China. (3), 2011.

[5] H. Ucbeyiay Sahinkaya, A. Ozkan, Investigation of shear flocculation behaviors of colemanite with some anionic surfactants and inorganic salts. Separation and Purification Technology. (1), 2011. 